\title{
Vertical Moist Thermodynamic Structure of the Madden-Julian Oscillation in Atmospheric Infrared Sounder Retrievals: An Update and a Comparison to ECMWF Interim Re-Analysis
}

\author{
Baijun Tian, Duane E. Waliser, And ERic J. Fetzer \\ Jet Propulsion Laboratory, California Institute of Technology, Pasadena, California \\ YUK L. YUNG \\ Division of Geological and Planetary Sciences, California Institute of Technology, Pasadena, California
}

(Manuscript received 4 May 2010, in final form 7 June 2010)

\begin{abstract}
The large-scale vertical moist thermodynamic structure of the Madden-Julian oscillation (MJO) was documented using the first $2.5 \mathrm{yr}$ (2002-05) of version 4 atmospheric specific humidity and temperature profiles from the Atmospheric Infrared Sounder (AIRS). In this study, this issue is further examined using currently available 7-yr version 5 AIRS data (2002-09) to test its dependence on the AIRS data record lengths, AIRS retrieval versions, and $\mathrm{MJO}$ event selection and compositing methods employed. The results indicate a strong consistency of the large-scale vertical moist thermodynamic structure of the MJO between different AIRS data record lengths ( 2.5 vs $7 \mathrm{yr}$ ), different AIRS retrieval versions (4 vs 5), and different MJO analysis methods [the extended empirical orthogonal function (EEOF) method vs the multivariate empirical orthogonal function (MEOF) method].

The large-scale vertical moist thermodynamic structures of the MJO between the AIRS retrievals and the ECMWF Interim Re-Analysis (ERA-Interim) products are also compared. The results indicate a much better agreement of the MJO vertical structure between AIRS and ERA-Interim than with the NCEP-NCAR reanalysis, although a significant difference exists in the magnitude of moisture anomalies between ERAInterim and AIRS. This characterization of the vertical moist thermodynamic structure of the MJO by AIRS and ERA-Interim offers a useful observation-based metric for general circulation model diagnostics.
\end{abstract}

\section{Introduction}

The Madden-Julian oscillation (MJO; Madden and Julian 1971, 1972) is the dominant form of intraseasonal (30-90 day) variability in the tropical atmosphere. The MJO interacts with, and influences, a wide range of weather and climate phenomena and represents an important source of predictability at the subseasonal time scale (Lau and Waliser 2005; Zhang 2005). However, the MJO is still not well understood (e.g., Wang 2005; Waliser 2006) or well represented in global circulation models (e.g., Lin et al. 2006; Zhang et al. 2006). Recently available satellite data have provided an excellent opportunity to study the MJO, especially its vertical structure (e.g.,

Corresponding author address: Baijun Tian, Jet Propulsion Laboratory, California Institute of Technology, MS 183-501, 4800 Oak Grove Dr., Pasadena, CA 91109.

E-mail: baijun.tian@jpl.nasa.gov
Myers and Waliser 2003; Fu et al. 2006; Tian et al. 2006; Yang et al. 2008). For example, Tian et al. (2006) documented the large-scale vertical moist thermodynamic structure of the MJO using the first 2.5-yr (2002-05; only 8 MJO events) version 4 (V4) atmospheric specific humidity and temperature profiles from the Atmospheric Infrared Sounder (AIRS) on the National Aeronautics and Space Administration (NASA) Aqua mission (Susskind et al. 2006). Here, we further examine this issue using the currently available $7 \mathrm{yr}$ of version 5 (V5) AIRS data (2002-09, 17 MJO events; Olsen et al. 2007) to test the dependence of the MJO vertical structure on the AIRS data record lengths, AIRS retrieval versions, and the MJO event selection and compositing methods employed. Tian et al. (2006) also compared the vertical structures of the MJO between AIRS and the National Centers for Environmental Prediction-National Center for Atmospheric Research (NCEP-NCAR) reanalysis, with the indication that NCEP-NCAR analysis was deficient in a 
number of areas, particularly in the Indian and Pacific Oceans. In this study, we perform a similar comparison between AIRS and the European Centre for MediumRange Weather Forecasts (ECMWF) Interim Re-Analysis (ERA-Interim; Simmons et al. 2007), a new global reanalysis dataset from ECMWF, to evaluate the performance of ERA-Interim in describing the large-scale vertical moist thermodynamic structure of the MJO.

\section{Data}

Three datasets were used for this study. The first is the global, daily (arithmetic mean of ascending and descending nodes) AIRS V5 level-3 atmospheric temperature and specific humidity profiles for the period of September 2002 to July 2009. The AIRS data have a horizontal $1^{\circ} \times 1^{\circ}$ resolution and are on 24 pressure levels from 1000 to $1 \mathrm{hPa}$ for temperature and 12 pressure layers from 1000 to $100 \mathrm{hPa}$ for specific humidity. The significant changes of AIRS V5 from V4 include, but are not limited to, new daytime nonlocal thermodynamic emission for the AIRS fast-forward model and improved quality indicators and error estimates (Olsen et al. 2007; Susskind 2007). As a result, a major improvement from V4 to V5 was the significantly improved yield of retrievals in more cloudy cases for AIRS level-3 products. The second is the global, daily (arithmetic mean of 4 times daily) ERA-Interim atmospheric temperature and specific humidity profiles for the same period as the AIRS data. The ERA-Interim data have a horizontal $1.5^{\circ} \times 1.5^{\circ}$ resolution and are on 37 pressure levels from 1000 to $1 \mathrm{hPa}$ (Simmons et al. 2007). The ERA-Interim assimilates cloud-screened radiances but not temperature and water vapor retrievals from AIRS since April 2003 (F. Vitart 2010, personal communication). The third is the Tropical Rainfall Measuring Mission (TRMM) 3B42 version 6 rainfall data from 1 January 1998 to 30 June 2009. The TRMM 3B42 data extends globally from $50^{\circ} \mathrm{S}$ to $50^{\circ} \mathrm{N}$ on $0.25^{\circ} \times 0.25^{\circ}$ grid boxes every $3 \mathrm{~h}$ (Huffman et al. 2007).

\section{MJO analysis methods}

Two MJO analysis methods (e.g., MJO event selection and compositing procedures) were employed for this study. Method 1 is the extended empirical orthogonal function (EEOF) method used by Waliser et al. (2003) and Tian et al. (2006). Briefly, all data were first binned into pentad (5 day) values and intraseasonal anomalies of the pentad data were obtained by removing the climatological seasonal cycle and filtering via a 30-90-day bandpass filter. Then, a pentad principal component (PC) time series from 1998 to 2009 was obtained by projecting the boreal winter (November-April) rainfall anomalies from 1998 to 2009 on the first EEOF mode of boreal winter rainfall anomalies from 1998 to 2005 in Tian et al. (2006, see their Fig. 1). Next, MJO events were chosen based on maxima in the pentad PC time series if their amplitudes are greater than +1 standard deviation. Figure 1a shows the selected 17 boreal winter MJO events from 2002 to 2009 (i.e., the AIRS period) including the same 8 MJO events in Tian et al. (2006, see their Fig. 2) from 2002 to January 2005. For each selected MJO event, the corresponding 11-pentad anomalies were extracted. A composite MJO cycle (11 pentads) was then obtained by averaging the selected MJO events.

Method 2, referred to as the multivariate EOF method, is introduced by Wheeler and Hendon (2004) and has been adopted widely by the MJO community (e.g., Kim et al. 2009; Waliser et al. 2009). Briefly, the intraseasonal anomalies of daily data were obtained by removing the climatological seasonal cycle and filtering via a 30-90-day bandpass filter. Then, a composite MJO cycle (8 phases) was calculated by averaging daily anomalies for each phase of the MJO cycle. The MJO phase for each day is determined by the Real-time Multivariate MJO (RMM) index (a pair of PC time series called RMM1 and RMM2; available online from 1974 to the present at http://cawcr. gov.au/staff/mwheeler/maproom/RMM/.) The RMM index is the projection of the daily observed National Oceanic and Atmospheric Administration (NOAA) outgoing longwave radiation (OLR) and NCEP-NCAR reanalysis and/or the Australian Bureau of Meteorology Research Center Global Analysis and Prediction (GASP) analysis of 850- and 200-hPa zonal winds, with the annual cycle and components of interannual variability removed, on a pair of multiple-variable EOFs. Two such EOFs are the leading pair of EOFs of the combined daily intraseasonal filtered fields of near-equatorially averaged $\left(15^{\circ} \mathrm{S}-15^{\circ} \mathrm{N}\right)$ NOAA OLR and NCEP-NCAR 850- and 200-hPa zonal winds for all seasons from 1979 to 2001 (23 yr), which describe the key features of the MJO. Figure $1 b$ shows the (RMM1, RMM2) phase space for all days in boreal winter from 2002 to 2009 and the number of days for each phase of the composite MJO cycle. Only days with strong MJO activity $\left(\mathrm{RMM} 1^{2}+\mathrm{RMM}^{2} \geq 1\right)$ are considered.

\section{Results}

Figure 2 shows the composite MJO cycle of equatorial mean $\left(8^{\circ} \mathrm{S}-8^{\circ} \mathrm{N}\right)$ pressure-longitude cross sections of specific humidity (left) and temperature (right) anomalies based on the 2.5-yr V5 AIRS data and the MJO analysis method 1. The overlaid solid black lines denote TRMM rainfall anomalies for the same period as the AIRS data. Here, the lags from -3 to +5 pentads of the MJO cycle are 


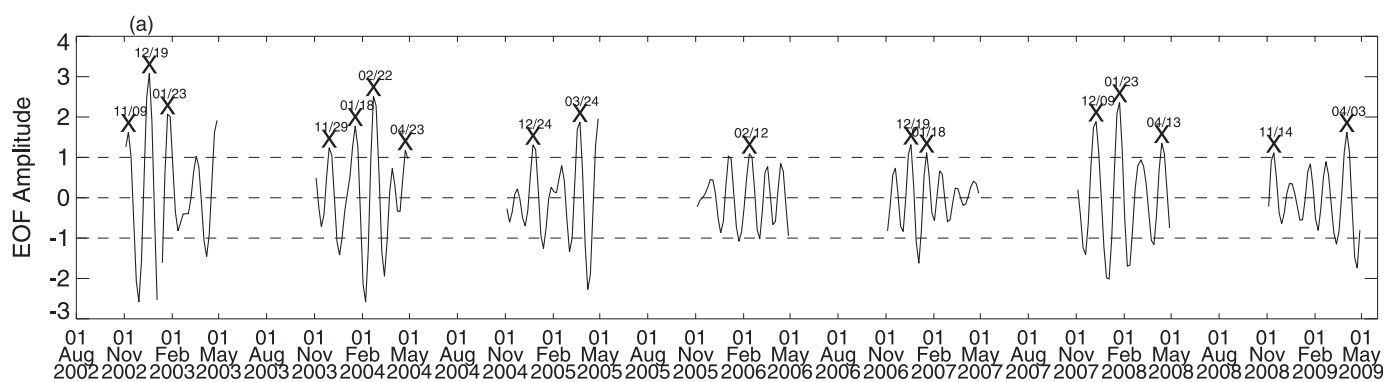

(b) (RMM1, RMM2) Phase Space

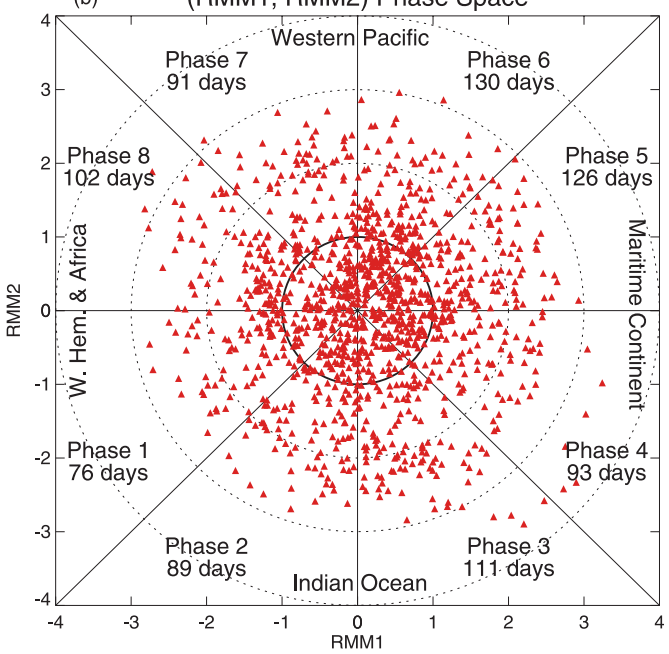

FIG. 1. (a) Pentad PC time series for the AIRS data period (2002-09) based on the first EEOF mode in Tian et al. (2006, see their Fig. 1). The crosses indicate the dates of 17 selected MJO events based on maxima in the PC time series. The dashed lines show the PC amplitude of \pm 1 and 0 . The unit for the lag is pentad. (b) The (RMM1, RMM2) phase space for all days in boreal winter from 2002 to 2009 and the number of days for each phase of the MJO cycle. Eight defined phases of the phase space are labeled to indicate the eastward propagation of the MJO in one MJO cycle. Also labeled are the approximate locations of the enhanced convective signal of the MJO for that location of the phase space (e.g., the "Indian Ocean" for phases 2 and 3).

shown and can be directly compared to Figs. 3 and 7 of Tian et al. (2006) and to our Figs. 3 and 4 shown later. The comparison of our Fig. 2 (V5) to Figs. 3 and 7 in Tian et al. (2006) (V4) indicates a consistent vertical moist thermodynamic structure of the MJO between AIRS V4 and V5. The correlation of the V4 and V5 anomalies is $\sim 0.88$ although $\mathrm{V} 5$ anomalies are consistently $\sim 20 \%$ larger than V4. The larger anomalies in V5 might be a result of the improved yield of retrievals in more cloudy cases in the level-3 product in V5 (Olsen et al. 2007; Susskind 2007).

Figure 3 shows the composite MJO cycle of equatorial mean pressure-longitude cross sections of specific humidity anomalies based on (a) the 7-yr V5 AIRS data and the MJO analysis method 1, (b) the 7-yr V5 AIRS data and the MJO analysis method 2, and (c) the 7-yr ERA-Interim data and the MJO analysis method 2. Figure 4 is similar to Fig. 3, but for temperature anomalies. For Figs. $3 \mathrm{a}$ and $4 \mathrm{a}$, the lags from -1 to +5 , and then -2 pentads of the MJO cycle, are shown and can be roughly compared to the phases $1-8$ of the MJO cycle in
Figs. $3 b, c$ and $4 b, c$ (i.e., lag -1 to phase 1 , lag 0 to phase 2 , and so on, and lag -2 to phase 8 ).

The comparison of Fig. 2 with Figs. 3a and 4a indicates that the large-scale vertical moist thermodynamic structure of the MJO is consistent between the 2.5- and 7-yr AIRS data records with a correlation of $\sim 0.9$ between them for both moisture and temperature. However, the 7 -yr moisture anomalies are $\sim 10 \%$ larger and the westward tilt structure with height is better defined over the Indian Ocean (IO) and Maritime Continent (MC) (west of $150^{\circ} \mathrm{E}$ ) but $\sim 10 \%$ smaller and the eastward tilt structure with height is less defined over the western-central Pacific. Furthermore, the 7-yr temperature anomalies are smaller over the Pacific although they are similar over the IO and MC.

The comparison of Figs. 3a and 4a with Figs. 3b and 4b also indicates a strong consistency in the vertical moist thermodynamic structure of the MJO between these two MJO analysis methods except for minor differences in magnitude. This demonstrates that the large-scale vertical 

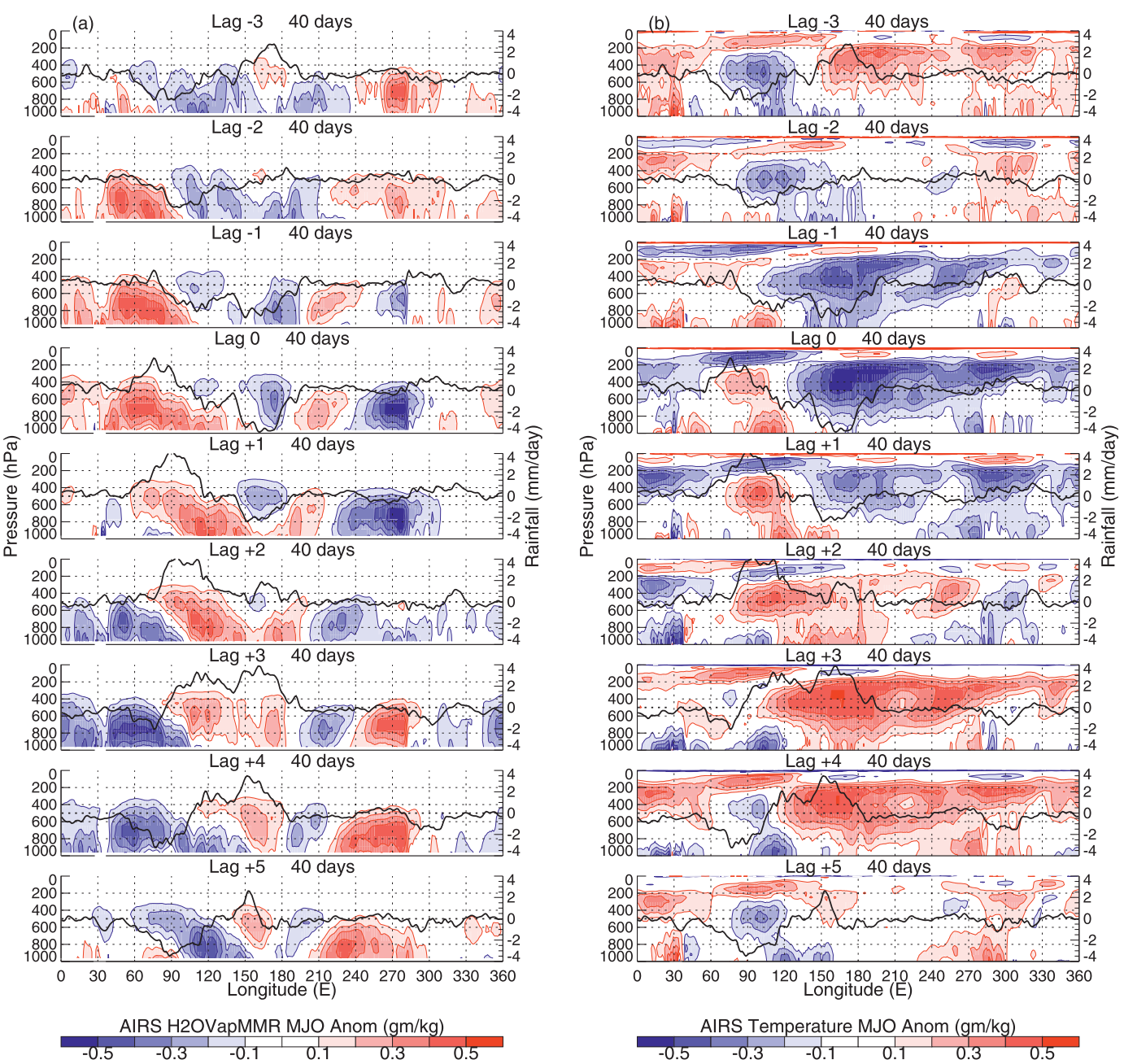

FIG. 2. Composite MJO cycle of equatorial mean $\left(8^{\circ} \mathrm{S}-8^{\circ} \mathrm{N}\right)$ pressure-longitude cross sections of (a) specific humidity and (b) temperature anomalies (color shading) based on the 2.5-yr pentad V5 AIRS data and the MJO analysis method 1. The overlaid solid black lines denote TRMM rainfall anomalies (scales at right) for the same period for the AIRS data.

moist thermodynamic structure of the MJO from AIRS, as indicated by this diagnostics, is independent of the MJO event selection and compositing method (method 1 versus 2) employed.

The major features of the large-scale vertical moist thermodynamic structure of the MJO from AIRS based on Figs. 3 and 4 can be summarized as follows. The moisture vertical structure is strongly dependent on longitude and convection. Over the IO and MC, where MJO convection anomaly is large, moisture anomalies exhibit a westward tilt structure with height and propagate eastward along the convection anomaly. Free-tropospheric (850-200 hPa) moist (dry) anomalies are generally associated with the convectively active (inactive) locations of the MJO with peaks around $700 \mathrm{hPa}$. During the transition locations of the MJO (weak convection anomaly between inactive and active locations; e.g., Kikuchi and Takayabu 2004;
Agudelo et al. 2006), moisture anomalies are mainly in the lower troposphere (below $500 \mathrm{hPa}$ ). As a result, enhanced convection is preceded (followed) by lower-tropospheric moist (dry) anomalies in both time ( $\sim 10$ days) and space ( $\sim 30^{\circ}$ longitude). Over the central-eastern Pacific, where the MJO convection anomaly is small, moisture anomalies are surprisingly large, especially along the coast of South America, and mainly confined in the lower troposphere (below $500 \mathrm{hPa}$ ). The moisture anomalies there exhibit an eastward tilt structure with height and propagate westward, totally different from the IO and MC. Over the western Pacific, moisture anomalies also exhibit an eastward tilt structure with height and seem to propagate westward similar to the central-eastern Pacific. Over the $\mathrm{IO}$ and $\mathrm{MC}$, temperature anomalies exhibit a trimodal vertical structure, that is, warm (cold) anomalies in the free troposphere (800-250 hPa) and cold (warm) anomalies 

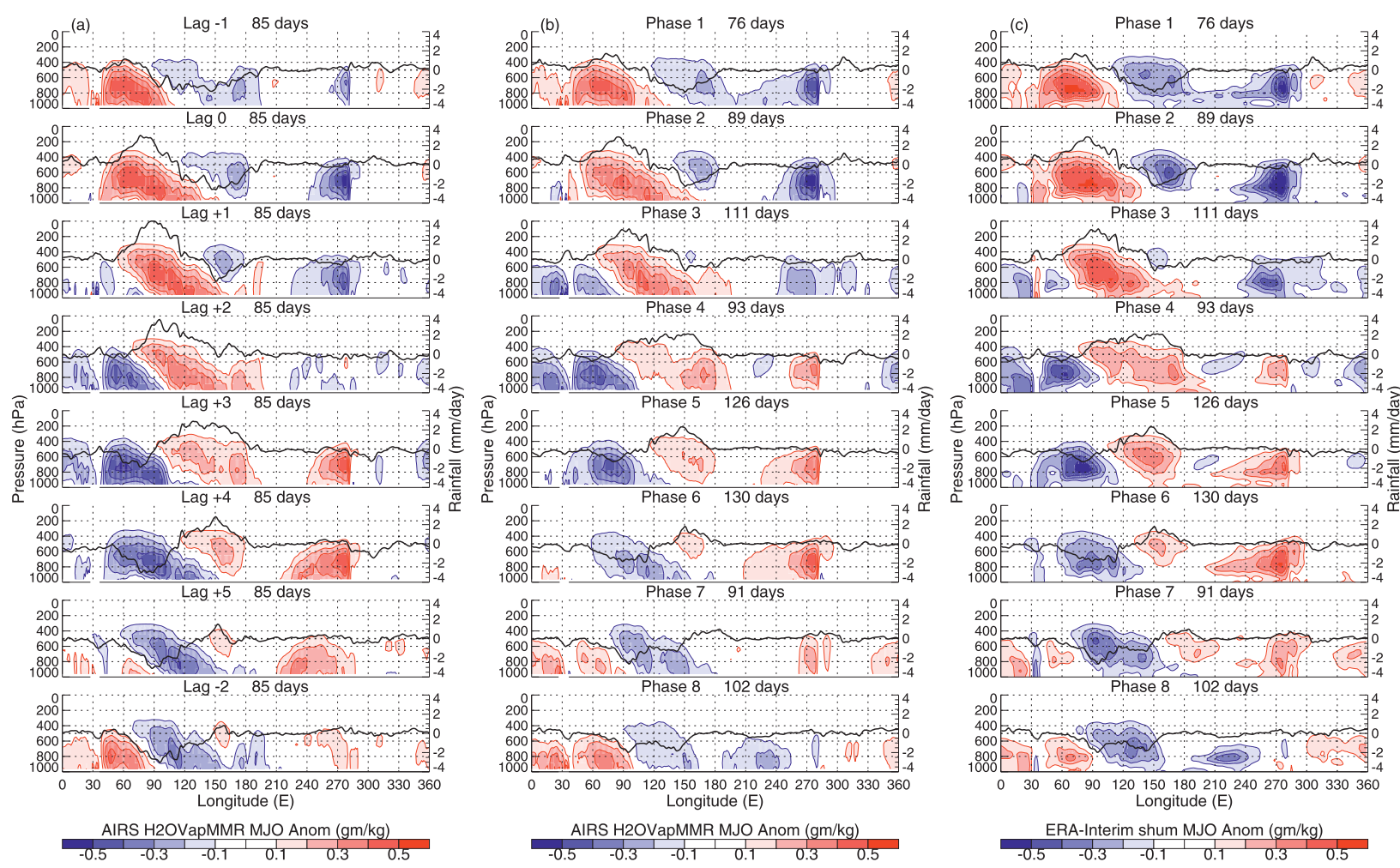

FIG. 3. Composite MJO cycle of equatorial mean $\left(8^{\circ} \mathrm{S}-8^{\circ} \mathrm{N}\right)$ pressure-longitude cross sections of specific humidity anomalies (color shading) based on (a) the 7-yr V5 pentad AIRS data and the MJO analysis method 1, (b) the 7-yr V5 daily AIRS data and the MJO analysis method 2, and (c) the 7-yr daily ERA-Interim data and the MJO analysis method 2. The overlaid solid black lines denote TRMM rainfall anomalies (scales at right) for the same period for the AIRS and ERA-Interim data.

near the tropopause (above $250 \mathrm{hPa}$ ) with a tilting structure and in the lower troposphere (below $800 \mathrm{hPa}$ ) associated with convectively enhanced (suppressed) locations of the MJO cycle. Enhanced convection is generally preceded (followed) in both time and space by low-level (below $800 \mathrm{hPa}$ ) warm (cold) anomalies. Over the Pacific, large temperature anomalies are mainly found in the free troposphere and near the tropopause with a bimodal vertical structure, which have the same sign as those over the western Pacific. This is consistent with previous observations from sounding data (e.g., Lin and Johnson 1996; Kemball-Cook and Weare 2001; Kiladis et al. 2005; Yoneyama et al. 2008; Katsumata et al. 2009).

The comparison of Figs. $3 b$ and $4 b$ with $3 c$ and $4 c$ indicates a general good agreement in the vertical structure of the MJO between AIRS and ERA-Interim, especially in the free troposphere, although significant differences are still evident especially in the boundary layer. The correlation between AIRS and ERA-Interim temperature anomalies is $>0.9$ in the stratosphere and upper troposphere (above $400 \mathrm{hPa}$ ), $\sim 0.7$ in the middle and lower troposphere, and $\sim 0.3$ in the boundary layer with ERA-Interim consistently smaller than AIRS, especially in the lower troposphere. The correlation between AIRS and ERA-Interim moisture anomalies is $\sim 0.95$ in the free troposphere (above $850 \mathrm{hPa}$ ) with ERA-Interim consistently $\sim 20 \%$ larger than AIRS, and $\sim 0.8$ in the boundary layer with ERA-Interim consistently $\sim 30 \%$ smaller than AIRS. In particular, the correlation between AIRS and ERA-Interim moisture anomalies is very poor (i.e., $\sim 0.3$ ) near the surface, especially over the leading edge of the low-level moisture anomalies, with ERA-Interim consistently $\sim 80 \%$ smaller than AIRS. Nevertheless, ERAInterim seems to be doing much better in depicting the vertical structure of the MJO than NCEP-NCAR in comparison to AIRS. The major deficiencies of NCEPNCAR highlighted in our earlier study seem to be mitigated, although not completely removed, in ERA-Interim. For example, temperature anomalies are much smaller in NCEP-NCAR (i.e., $\pm 0.2 \mathrm{~K}$ ) but at least comparable in ERA-Interim and AIRS (i.e., $\pm 0.4 \mathrm{~K}$ ). The anomalous lower-troposphere temperature structure is still less well defined in ERA-Interim than in AIRS, similar to NCEPNCAR. However, the opposite temperature anomalies in the IO compared to AIRS in NCEP-NCAR is absent in ERA-Interim. Moreover, the well-defined eastward-tilting moisture structure with height over the central-eastern Pacific found in both AIRS and ERA-Interim is less well 

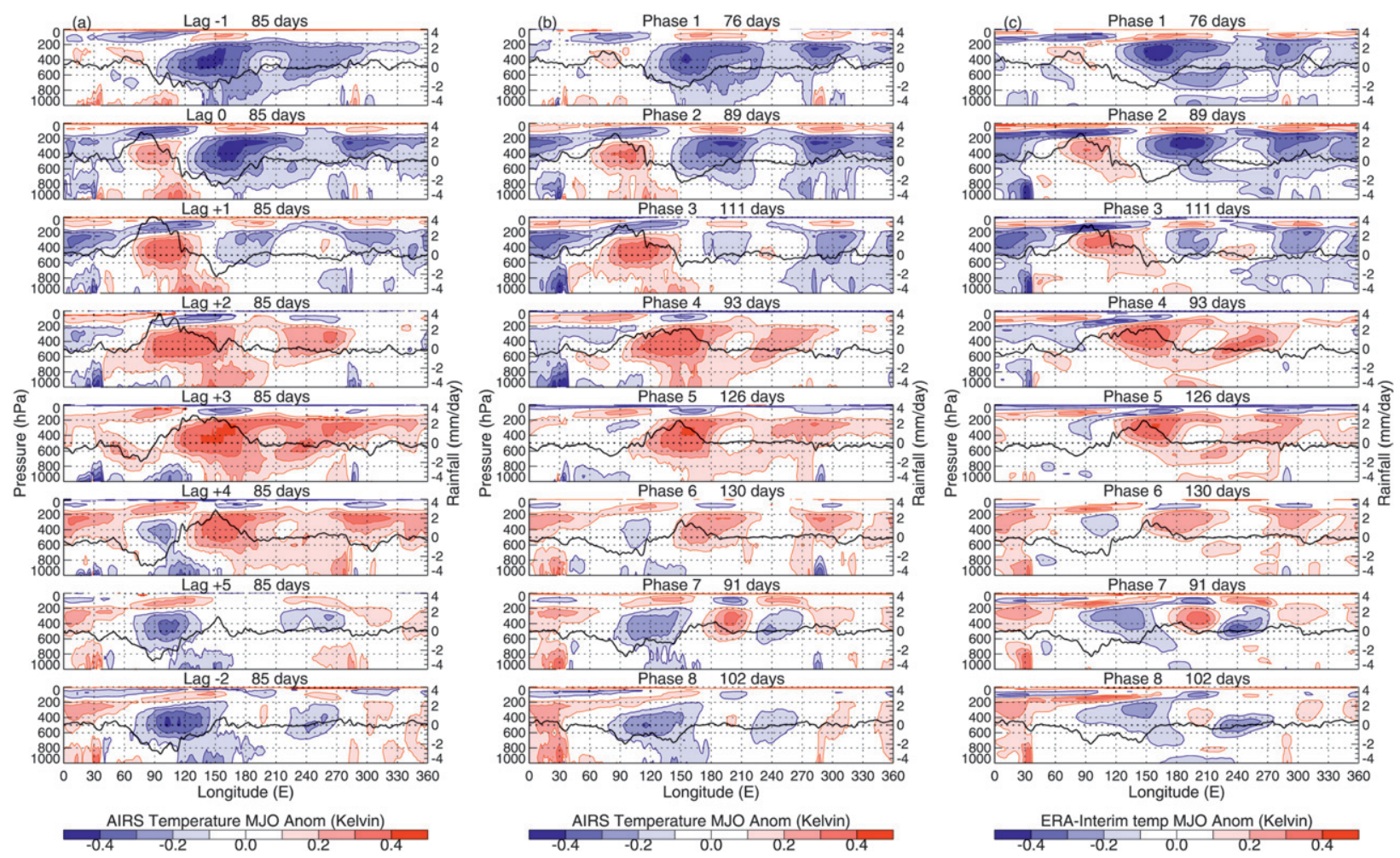

FIG. 4. As in Fig. 3, but for temperature anomalies.

defined or even absent in NCEP-NCAR. In addition, the positive correlation between midtropospheric moisture anomalies and precipitation anomalies found in AIRS but absent in NCEP-NCAR is also evident in ERA-Interim. The close agreement of the MJO vertical moist thermodynamic structure between AIRS and ERA-Interim is not unexpected because ERA-Interim assimilates cloudscreened radiances from AIRS since April 2003. The improvement from NCEP-NCAR to ERA-Interim is due probably to better models used in ERA-Interim (Simmons et al. 2007).

\section{Summary}

The large-scale vertical moist thermodynamic structure of the MJO from our earlier study (Tian et al. 2006) was further examined here using the currently available 7-yr V5 AIRS data (2002-09). The current analysis indicates a strong consistency of the vertical structure of the MJO between different AIRS data record lengths ( $2.5 \mathrm{vs} 7 \mathrm{yr}$ ), different AIRS retrieval versions (4 vs 5), and different MJO event selection and compositing methods [the EEOF method used by Tian et al. (2006) vs the MEOF method used by Wheeler and Hendon (2004)]. Furthermore, the comparison between AIRS and ERA-Interim data indicates that differences exist between ERA-Interim and AIRS, especially the magnitude of moisture anomalies. However, the agreement between ERA-Interim and AIRS seems to be much better than that in NCEPNCAR and AIRS and ERA-Interim does pretty well in describing the vertical moist thermodynamic structure of the MJO. This characterization of the vertical structure of the MJO by AIRS and ERA-Interim offers a useful observation-based metric for global circulation model diagnostics of MJO representations (e.g., Waliser et al. 2009).

Acknowledgments. This research was carried out at JPL/Caltech under a contract with NASA and supported by the AIRS project at JPL and the NSF through Grant ATM-0840755 to UCLA. Comments from M. Wheeler, three anonymous reviewers, and conversations with P. Bauer, M. Goldberg, B. Kahn, E. Manning, E. Olsen, J. Susskind, J. Teixeira, and F. Vitart all helped to improve this paper.

\section{REFERENCES}

Agudelo, P. A., J. A. Curry, C. D. Hoyos, and P. J. Webster, 2006: Transition between suppressed and active phases of intraseasonal oscillations in the Indo-Pacific warm pool. J. Climate, 19, 5519-5530. 
Fu, X. H., B. Wang, and L. Tao, 2006: Satellite data reveal the 3-D moisture structure of tropical intraseasonal oscillation and its coupling with underlying ocean. Geophys. Res. Lett., 33, L03705, doi:10.1029/2005GL025074.

Huffman, G. J., and Coauthors, 2007: The TRMM Multisatellite Precipitation Analysis (TMPA): Quasi-global, multiyear, combined-sensor precipitation estimates at fine scales. $J$. Hydrometeor., 8, 38-55.

Katsumata, M., R. H. Johnson, and P. E. Ciesielski, 2009: Observed synoptic-scale variability during the developing phase of an ISO over the Indian Ocean during MISMO. J. Atmos. Sci., 66, 3434-3448.

Kemball-Cook, S. R., and B. C. Weare, 2001: The onset of convection in the Madden-Julian oscillation. J. Climate, 14, 780-793.

Kikuchi, K., and Y. N. Takayabu, 2004: The development of organized convection associated with the MJO during TOGA COARE IOP: Trimodal characteristics. Geophys. Res. Lett., 31, L10101, doi:10.1029/2004GL019601.

Kiladis, G. N., K. H. Straub, and P. T. Haertel, 2005: Zonal and vertical structure of the Madden-Julian oscillation. J. Atmos. Sci., 62, 2790-2809.

Kim, D., and Coauthors, 2009: Application of MJO simulation diagnostics to climate models. J. Climate, 22, 6413-6436.

Lau, W. K. M., and D. E. Waliser, 2005: Intraseasonal Variability of the Atmosphere-Ocean Climate System. Springer, 474 pp.

Lin, J. L., and Coauthors, 2006: Tropical intraseasonal variability in 14 IPCC AR4 climate models. Part I: Convective signals. J. Climate, 19, 2665-2690.

Lin, X., and R. H. Johnson, 1996: Heating, moistening, and rainfall over the western Pacific warm pool during TOGA COARE. J. Atmos. Sci., 53, 3367-3383.

Madden, R. A., and P. R. Julian, 1971: Detection of a 40-50 day oscillation in the zonal wind in the tropical Pacific. J. Atmos. Sci., 28, 702-708.

— tropics with a 40-50 day period. J. Atmos. Sci., 29, 1109-1123.

Myers, D. S., and D. E. Waliser, 2003: Three-dimensional water vapor and cloud variations associated with the Madden-Julian oscillation during Northern Hemisphere winter. J. Climate, 16, 929-950.

Olsen, E. T., and Coauthors, cited 2007: AIRS/AMSU/HSB version 5 data release user guide. [Available online at http://disc. sci.gsfc.nasa.gov/AIRS/documentation/v5_docs/.]
Simmons, A., S. Uppala, D. Dee, and S. Kobayashi, 2007: ERAInterim: New ECMWF reanalysis products from 1989 onwards. ECMWF Newsletter, No. 110, ECMWF, Reading, United Kingdom, 25-35.

Susskind, J., 2007: Improved atmospheric soundings and error estimates from analysis of AIRS/AMSU data. Atmospheric and Environmental Remote Sensing Data Processing and Utilization III: Readiness for GEOSS, M. D. Goldberg et al., Eds., International Society for Optical Engineering (SPIE Proceedings, Vol. 6684), 66840M-66840M-12.

—_, and Coauthors, 2006: Accuracy of geophysical parameters derived from Atmospheric Infrared Sounder/Advanced Microwave Sounding Unit as a function of fractional cloud cover. J. Geophys. Res., 111, D09S17, doi:10.1029/2005JD006272.

Tian, B., D. E. Waliser, E. J. Fetzer, B. H. Lambrigtsen, Y. L. Yung, and B. Wang, 2006: Vertical moist thermodynamic structure and spatial-temporal evolution of the MJO in AIRS observations. J. Atmos. Sci., 63, 2462-2485.

Waliser, D. E., 2006: Intraseasonal variability. The Asian Monsoon, B. Wang, Ed., Springer/Praxis, 203-257.

—, K. M. Lau, W. Stern, and C. Jones, 2003: Potential predictability of the Madden-Julian oscillation. Bull. Amer. Meteor. Soc., 84, 33-50.

- and Coauthors, 2009: MJO simulation diagnostics. J. Climate, 22, 3006-3030.

Wang, B., 2005: Theory. Intraseasonal Variability of the AtmosphereOcean Climate System, W. K. M. Lau and D. E. Waliser, Eds., Springer, 307-360.

Wheeler, M. C., and H. H. Hendon, 2004: An all-season real-time multivariate MJO index: Development of an index for monitoring and prediction. Mon. Wea. Rev., 132, 1917-1932.

Yang, B., X. H. Fu, and B. Wang, 2008: Atmosphere-ocean conditions jointly guide convection of the boreal summer intraseasonal oscillation: Satellite observations. J. Geophys. Res., 113, D11105, doi:10.1029/2007jd009276.

Yoneyama, K., and Coauthors, 2008: MISMO field experiment in the equatorial Indian Ocean. Bull. Amer. Meteor. Soc., 89, 1889-1903.

Zhang, C. D., 2005: Madden-Julian Oscillation. Rev. Geophys., 43, RG2003, doi:10.1029/2004RG000158.

_ cillation in four pairs of coupled and uncoupled global models. Climate Dyn., 27, 573-592, doi:10.1007/s00382-006-0148-2. 